\title{
Expression of pAkt is associated with a poor prognosis in Chinese women with invasive ductal breast cancer
}

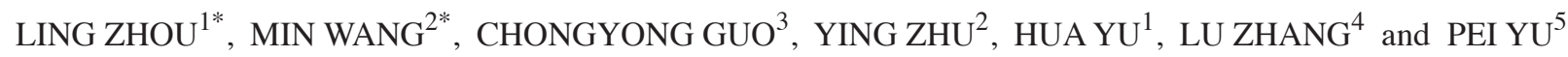 \\ Departments of ${ }^{1}$ Surgery and ${ }^{2}$ Pathology, Branch of Shanghai First People's Hospital, Shanghai 200081; ${ }^{3}$ Department of \\ General Surgery, Binzhou People's Hospital, Binzhou, Shandong 256600; ${ }^{4}$ Department of General Surgery, \\ The First Affiliated Hospital of Nanjing Medical University, Nanjing, Jiangsu 210029; ${ }^{5}$ Department of Orthopedics, \\ Shanghai Ruijin Hospital Affiliated to Shanghai Jiaotong University School of Medicine, Shanghai 210025, P.R. China
}

Received July 28, 2016; Accepted January 3, 2018

DOI: $10.3892 / \mathrm{ol} .2018 .7965$

\begin{abstract}
Over the past three decades, numerous patients with breast cancer succumbed to cancer metastasis and recurrence, while, the exact mechanisms underlying this malignancy, and the potential biomarkers for prognosis prediction remain elusive. It was previously demonstrated that phosphorylated $\mathrm{RAC}-\alpha$ serine/threonine-protein kinase (pAkt) and Beclin 1 was associated with cancer metastasis, and recurrence. Thus far, the expression patterns of pAkt and Beclin 1 in breast cancer tissues, and their associations with the prognosis of invasive ductal breast cancer remain inconclusive, which may be due to various factors, including ethnicity and pathological types. In the present study, a total of 90 Chinese female patients with invasive ductal breast cancer between June 1999 and August 2002 were enrolled at Shanghai First People's Hospital (Shanghai, China). The patients were followed up from 5 months to 13.5 years for survival analysis. The expressional levels of pAkt and Beclin 1 in invasive ductal breast cancer tissues, and the normal paracancerous tissues were measured by immunohistochemistry. Associations with prognosis following surgery were further evaluated using Cox regression analysis. In 90 invasive ductal breast cancer samples, pAkt was detected in 17 (18.9\%) samples and Beclin 1 in 33 (36.7\%) samples, but both were not detected in any of the paracancerous samples. Survival analysis revealed that pAkt expression carried a
\end{abstract}

Correspondence to: Dr Pei Yu, Department of Orthopedics, Shanghai Ruijin Hospital Affiliated to Shanghai Jiaotong University School of Medicine, 2 Ruijin Road, Shanghai 210025, P.R. China

E-mail: yupei_ortho@163.com

Dr Lu Zhang, Department of General Surgery, The First Affiliated Hospital of Nanjing Medical University, 300 Guangzhou Road, Nanjing, Jiangsu 210029, P.R. China

E-mail: z1791221@163.com

*Contributed equally

Key words: invasive ductal breast cancer, phosphorylated RAC- $\alpha$ serine/threonine-protein kinase, Beclin 1, biomarker, prognosis tendency to predict a shorter disease-free survival (DFS) in patients with invasive ductal breast cancer. Additionally, Beclin 1 expression was not significantly associated with survival. Furthermore, univariate Cox regression analysis demonstrated that pAkt expression was negatively associated with DFS and overall survival. Multivariate Cox regression analysis indicated that pAkt expression was an independent risk factor associated with poor prognosis in patients with invasive ductal breast cancer (all $\mathrm{P}<0.05$ ). pAkt may be used as a potential prognostic biomarker in Chinese women with invasive ductal breast cancer.

\section{Introduction}

Breast cancer is a major public health concern, and remains the most prevalent cancer type and a major cause of cancer-associated mortality in women worldwide (1). Invasive ductal carcinomas represent $-75 \%$ of all breast cancer cases (2). In the United States, the breast cancer incidence is $120.7 / 100,000$ women with the breast cancer mortality rate being 24/100,000 women; the lifetime risk of breast cancer is $12.2 \%$ (3). Although, the breast cancer incidence in China is significantly lower compared with that in the United States (4), previous models suggest that breast cancer may soon reach epidemic proportions (5). Over the past three decades, numerous patients have succumbed to cancer metastasis and recurrence despite comprehensive advances achieved in the treatment of breast cancer. A number of risk factors have been identified to be associated with the initiation and progress of breast cancer (6), including a shift to a western diet and increased stress (7). However, the exact mechanisms underlying this malignancy and the potential biomarkers for prognosis prediction remain to be elucidated.

Phosphorylated RAC- $\alpha$ serine/threonine-protein kinase (pAkt), the activated form of Akt, also known as protein kinase $\mathrm{B}$, is a major downstream effector of the phosphatidylinositide 3-kinase (PI3K) pathway. It serves an essential role in the development, progression and metastatic spread of breast cancer $(8,9)$. Extensive preclinical evidence has indicated that PI3K/Akt pathway inhibition may sensitize breast cancer cells to doxorubicin $(10,11)$. Furthermore, previous studies have indicated that the expression of pAkt is 
associated with the prognosis in breast cancer (8-11), although the results have been controversial $(8,12-15)$. The expression of pAkt was revealed to be negatively correlated with the prognosis of breast cancer (12-14), which contrasted with the results demonstrated by another study (15). The variance in results may be due to the different ethnicities and pathological types of patients included in each study.

Autophagy is the process of self-digestion in which lysosomal degradation is used to maintain cellular viability during periods of metabolic stress, including starvation; however, its role in the growth of cancer remains controversial $(16,17)$. Beclin 1 is an essential component for inducing autophagy in a variety of cancer types (18). It was demonstrated that the levels of Beclin 1 in breast cancer cells were significantly lower compared with those in normal breast epithelial cells (18); however, the expression pattern of Beclin 1 in breast cancer tissue and its association with the prognosis of patients has not been extensively studied.

In the present study, a total of 90 Chinese female patients with invasive ductal breast cancer were enrolled between June 1999 and August 2002 at Shanghai First People's Hospital (Shanghai, China). The expression patterns of pAkt and Beclin 1 in invasive ductal breast cancer tissues were measured. In addition, their associations with the prognosis of patients following surgery were evaluated using Cox regression analysis.

\section{Materials and methods}

Patients and tissue specimens. A total of 90 Chinese female patients with invasive ductal breast cancer were enrolled in the present study between June 1999 and August 2002 at Shanghai First People's Hospital. At the time of surgery, the mean age of patients was 55.68 \pm 12.18 years (range, 27-82 years). A complete diagnostic evaluation consisting of chest X-rays, mammography, ultrasounds of the liver and a whole-body bone scan prior to surgery was performed for each patient to exclude the presence of distant metastasis. No patients had received radiotherapy or neoadjuvant therapy prior to surgery. The cancer tissue specimens and normal paracancerous tissues were collected in liquid nitrogen during surgery. All samples were confirmed by pathological examination. Pathological information was obtained for the following: Histological tumor type, primary tumor size, estrogen receptor (ER) status, progesterone receptor (PR) status, axillary lymph node status and clinical stage. The clinical stage was classified according to the American Joint Committee on Cancer tumor node metastasis staging system (19). The present study was approved by the Ethical Committee and Institutional Review Board of Shanghai First People's Hospital. Written informed consent was obtained from all patients for the use of their samples in the present study.

Immunohistochemistry. Formalin-fixed paraffin-embedded tissue sections were deparaffinized in xylene, rehydrated through graded ethanol and then boiled at $99^{\circ} \mathrm{C}$ for $10 \mathrm{~min}$ in citrate buffer (10 mM, pH 6.0) for antigen retrieval. Endogenous peroxidase activity was suppressed by incubation with $3 \%$ hydrogen peroxide for $10 \mathrm{~min}$ at room temperature (RT). Slides were then blocked with $5 \%$ bovine serum albumin at
Table I. Summary of clinicopathological characteristics of 90 patients with breast cancer.

\begin{tabular}{|c|c|}
\hline Characteristics & Value \\
\hline \multicolumn{2}{|l|}{ Mean age (years) } \\
\hline Age range, years $(\mathrm{n} / \%)$ & $55.68 \pm 12.18$ \\
\hline$<50$ & $31 / 34.4$ \\
\hline$\geq 50$ & $59 / 65.6$ \\
\hline \multicolumn{2}{|c|}{ Lymph node metastasis $(\mathrm{n} / \%)$} \\
\hline Positive & $36 / 40$ \\
\hline Negative & $54 / 60$ \\
\hline \multicolumn{2}{|l|}{ Tumor size, $\mathrm{cm}(\mathrm{n} / \%)$} \\
\hline$<2$ & $33 / 36.7$ \\
\hline$\geq 2$ and $<5$ & $49 / 54.4$ \\
\hline$\geq 5$ & $8 / 8.9$ \\
\hline \multicolumn{2}{|l|}{ ER status $(\mathrm{n} / \%)$} \\
\hline Positive & $55 / 61.1$ \\
\hline Negative & $35 / 38.9$ \\
\hline \multicolumn{2}{|l|}{ PR status $(\mathrm{n} / \%)$} \\
\hline Positive & $48 / 53.3$ \\
\hline Negative & $42 / 46.7$ \\
\hline \multicolumn{2}{|l|}{ HER2 status (n/\%) } \\
\hline Positive & $19 / 21.1$ \\
\hline Negative & $71 / 78.9$ \\
\hline \multicolumn{2}{|l|}{ TNBC (n/\%) } \\
\hline Yes & $20 / 22.2$ \\
\hline No & $70 / 77.8$ \\
\hline \multicolumn{2}{|l|}{ Clinical stage $(\mathrm{n} / \%)$} \\
\hline I & $23 / 25.6$ \\
\hline II & $53 / 58.8$ \\
\hline III & $14 / 15.6$ \\
\hline
\end{tabular}

ER, estrogen receptor; PR, progesterone receptor; HER2, human epidermal growth factor receptor 2; TNBC, triple-negative breast cancer.

RT for 60 min (Wuhan Boster Biological Technology, Co., Ltd., Wuhan, China), incubated with diluted primary antibodies against pAkt (1:500; cat. no. ab38449) and Beclin 1 (1:500; cat. no. ab62557) (both from Abcam, Cambridge, MA, USA) for $1 \mathrm{~h}$ at $37^{\circ} \mathrm{C}$, and then incubated with the secondary antibody (horseradish peroxidase-conjugated anti-rabbit IgG; cat. no. ab205718; Abcam) for $20 \mathrm{~min}$ at $37^{\circ} \mathrm{C}$. Slides were visualized with diaminobenzidine and counterstained with hematoxylin at RT for 2-3 min for light microscopic examination at 200-fold magnification, (CX31; Olympus Corporation, Tokyo, Japan). The intensity of staining was scored from 1 to 3 (1, no staining or light brown staining; 2 , weak to moderate brown staining; and 3 , moderate to strong brown staining). The percentage of positive cells was calculated from 10 random fields. The intensity of staining and the percentage of positive staining were used to evaluate protein expression. Cases with $\geq 10 \%$ positive cells and scores $\geq 2$ were considered positive. 

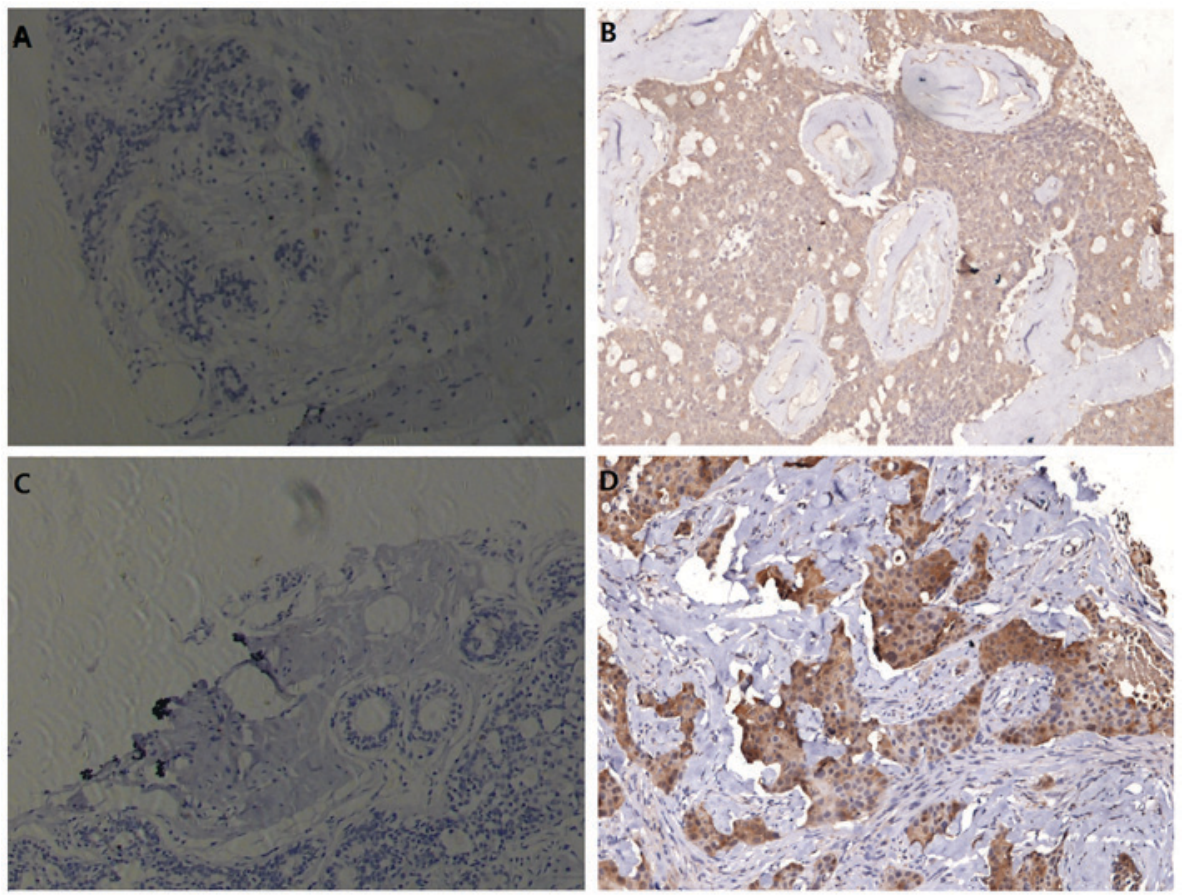

Figure 1. Expression of pAkt and Beclin 1 ininvasive ductal breast cancer samples. (A) pAkt was not detected in the normal paracancerous samples.(B) pAkt was detected in invasive ductal breast cancer samples, and the positive staining in brown was primarily localized to the cytoplasm with some positive staining on the membrane. (C) Beclin 1 was not detected in the normal paracancerous samples. (D) Beclin 1 was detected in invasive ductal breast cancer samples, and the positive staining shown in brown wasprimarily localized to the cytoplasm with some positive staining on the membrane. Original magnification, $\mathrm{x} 100$. pAkt, phosphorylated RAC- $\alpha$ serine/threonine-protein kinase.

Follow-up. Patients were followed up until June 30, 2016. Patients were given a physical examination every 3 months for the first 2 years after surgery and were subsequently examined every 6 months. Disease-free survival (DFS) was calculated as the duration between the date of surgery and the date of first evidence of local recurrence, distant metastasis, or diagnosis of a second primary tumor or cancer-associated mortality. Overall survival (OS) was calculated as the time between the date of surgery and the date of mortality from any cause.

Statistical analysis. SPSS software (version 19.0; IBM Corp., Armonk, NY, USA) was used for all statistical analysis. The Chi-square test or Fisher's exact test was applied for univariate analysis to determine the association between the expression of pAkt and Beclin 1 with clinicopathological parameters. Survival curves were calculated using the Kaplan-Meier estimator method and comparisons were performed using the log-rank tests. The univariate Cox regression was used to identify potential factors associated with the prognosis, then factors with $\mathrm{P}<0.1$ in the univariate analysis were included in the multivariate Cox regression analysis to determine the independent prognostic factors and explore their effects. All $\mathrm{P}$-values presented are two-tailed. $\mathrm{P}<0.05$ was considered to indicate a statistically significant difference.

\section{Results}

Patient characteristics. A total of 90 female patients with invasive ductal carcinoma of the breast were enrolled in the present study. Among the 90 breast cancer tissues, 36 (40\%) were identified with lymph node metastasis, and $54(60 \%)$ without lymph node metastasis. For tumor size, there were 33 patients with tumor size $<2 \mathrm{~cm}, 49$ patients with tumor size $\geq 2$ and $<5 \mathrm{~cm}$, and 8 patients with tumor size $\geq 5 \mathrm{~cm}$. A total of $55(61.1 \%)$ patients were identified as ER-positive, 48 (53.3\%) as PR-positive, and 19 (21.1\%) as human epidermal growth factor receptor 2 (HER2)-positive. In addition, there were 20 patients with triple-negative breast cancer. There were $23(25.6 \%)$ patients with clinical stage I, 53 (58.8\%) with clinical stage II, and 14 (15.6\%) with clinical stage III. The clinicopathological characteristics of the patients are presented in Table I.

Expression pattern of pAkt and Beclin 1, and their association with clinicopathological parameters. In 90 invasive ductal breast cancer samples, pAkt expression was detected in 17 (18.9\%) samples and Beclin 1 in 33 (36.7\%) samples, both of which were not detected in normal paracancerous samples (Fig. 1). The positive reaction for pAkt and Beclin 1 were primarily localized to the cytoplasm with slight positive staining on the membrane.

The association between protein expression and clinicopathological parameters was analyzed. As presented in Tables II and III, no significant associations were identified between the expression levels of pAkt and Beclin 1, and any clinicopathological parameters.

Risk factors associated with patient survival. All 90 patients were followed up from 5 months to 13.5 years (mean period, 107.8 months). A total of 10 mortalities (6 patients with lymph node metastasis and 4 patients without lymph node metastasis) and 4 recurrences ( 2 patients with lymph node 
Table II. Association between pAkt expression and clinicopathologic parameters.

\begin{tabular}{lll}
\hline & $\mathrm{pAkt}$ & \\
\cline { 2 - 3 } Characteristics & Negative Positive Total P-value
\end{tabular}

\begin{tabular}{llll}
\hline Total case & 73 & 17 & 82
\end{tabular}

Age, years

$\begin{array}{lrrrr}<50 & 28 & 3 & 31 & 0.156 \\ \geq 50 & 45 & 14 & 59 & \end{array}$

Tumor size, $\mathrm{cm}$

$<2$
$\geq 2$ and $<5$
$\geq 5$

$\begin{array}{rrr}28 & 5 & 33 \\ 39 & 10 & 49 \\ 6 & 2 & 8\end{array}$

Lymph node status

$\begin{array}{llll}\text { Negative } & 45 & 9 & 54 \\ \text { Positive } & 28 & 8 & 36\end{array}$

Clinical stage

\begin{tabular}{lrrrr} 
I & 18 & 5 & 23 & 0.854 \\
II & 43 & 10 & 53 & \\
III & 12 & 2 & 14 & \\
ER & & & & \\
Negative & 26 & 9 & 35 & 0.269 \\
Positive & 47 & 8 & 55 & \\
PR & & & & \\
Negative & 31 & 11 & 42 & 0.113 \\
Positive & 42 & 6 & 48 & \\
HER2 & & & & \\
Negative & 59 & 12 & 71 & 0.342 \\
Positive & 14 & 5 & 19 & \\
TNBC & & & & 0.518 \\
Yes & 15 & 5 & 20 & \\
No & 58 & 12 & 70 & \\
\hline
\end{tabular}

ER, estrogen receptor; PR, progesterone receptor; HER2, human epidemal growth factor receptor 2; TNBC, triple-negative breast cancer; pAkt, phosphorylated RAC- $\alpha$ serine/threonine-protein kinase.

metastasis and 2 patients without lymph node metastasis) were reported during this period. Survival analysis revealed that patients with pAkt expression exhibited significantly shorter DFS times compared with those negative for $\mathrm{pAkt}$ (97.12 vs. 150.64 years; $\mathrm{P}<0.001$; Fig. 2A). Furthermore, a trend was observed between pAkt expression and shorter OS times, but it did not reach statistical significance (128.63 years vs. 151.32 years; $\mathrm{P}=0.071)$. In addition, patient and shorter clinical stage I-II had significantly longer DFS (146.15 years) and OS (153.70 years) times compared with those in clinical stage III (DFS, 111.79 years; and OS, 116.21 years) $(\mathrm{P}=0.019$ and $\mathrm{P}=0.001$, respectively; Fig. $2 \mathrm{~B}$ and $\mathrm{C}$ ).

To determine the risk factors associated with the survival, univariate Cox regression analysis was performed for several potential factors, including age, tumor size, lymph node status, clinical stage, ER status, PR status and HER2 status,
Table III. Association between Beclin 1 expression and clinicopathologic parameters.

\begin{tabular}{|c|c|c|c|c|}
\hline \multirow[b]{2}{*}{ Characteristics } & \multicolumn{2}{|c|}{ Beclin 1} & \multirow[b]{2}{*}{ Total } & \multirow[b]{2}{*}{ P-value } \\
\hline & Negative & Positive & & \\
\hline Total case & 57 & 33 & 90 & \\
\hline \multicolumn{5}{|l|}{ Age, years } \\
\hline$<50$ & 22 & 9 & 31 & 0.359 \\
\hline$\geq 50$ & 35 & 24 & 59 & \\
\hline \multicolumn{5}{|l|}{ Tumor size, $\mathrm{cm}$} \\
\hline$<2$ & 21 & 12 & 33 & 0.998 \\
\hline$\geq 2$ and $<5$ & 31 & 18 & 49 & \\
\hline$\geq 5$ & 5 & 3 & 8 & \\
\hline \multicolumn{5}{|c|}{ Lymph node status } \\
\hline Negative & 32 & 22 & 54 & 0.377 \\
\hline Positive & 25 & 11 & 36 & \\
\hline \multicolumn{5}{|l|}{ Clinical stage } \\
\hline I & 16 & 7 & 23 & 0.518 \\
\hline II & 31 & 22 & 53 & \\
\hline III & 10 & 4 & 14 & \\
\hline \multicolumn{5}{|l|}{ ER } \\
\hline Negative & 20 & 5 & 35 & 0.295 \\
\hline Positive & 37 & 18 & 55 & \\
\hline \multicolumn{5}{|l|}{ PR } \\
\hline Negative & 25 & 17 & 42 & 0.517 \\
\hline Positive & 32 & 16 & 48 & \\
\hline \multicolumn{5}{|l|}{ HER2 } \\
\hline Negative & 45 & 26 & 71 & 0.986 \\
\hline Positive & 12 & 7 & 19 & \\
\hline TNBC & & & & 0.068 \\
\hline Yes & 9 & 11 & 20 & \\
\hline No & 48 & 22 & 70 & \\
\hline
\end{tabular}

ER, estrogen receptor; PR, progesterone receptor; HER2, human epidermal growth factor receptor 2; TNBC, triple-negative breast cancer.

expression of pAkt, and Beclin 1. The results revealed that pAkt expression was negatively associated with DFS [hazard ratio (HR), 0.148; 95\% confidence interval (CI), 0.051-0.427; $\mathrm{P}<0.001]$ and $\mathrm{OS}$ times (HR, 0.331; 95\% CI, 0.093-1.173; $\mathrm{P}=0.087)$. Furthermore, clinical stage III was negatively associated with both DFS [HR=0.293, 95\% CI=0.098-0.874, $\mathrm{P}=0.028]$ and $\mathrm{OS}[\mathrm{HR}=0.165,95 \% \mathrm{CI}=0.048-0.571, \mathrm{P}=0.004]$. Other factors were not associated with survival (Table IV). Then, multivariate Cox regression analysis was conducted, and the results indicated that pAkt expression was independently associated with DFS (HR, 0.208; 95\% CI, 0.067-0.646; $\mathrm{P}=0.007$ ) and $\mathrm{OS}$ times (HR, 0.246; 95\% CI, 0.067-0.911; $\mathrm{P}=0.036)$. Additionally, clinical stage III was an independent risk factor associated with DFS (HR, 0.208; 95\% CI, 0.067-0.646; $\mathrm{P}=0.007)$ and $\mathrm{OS}$ times $(\mathrm{HR}, 0.134 ; 95 \% \mathrm{CI}$, 0.037-0.482; $\mathrm{P}=0.002$ ) (Table V). 
Table IV. Univariate Cox regression analysis of survival of 90 patients with breast cancer.

Univariate Cox regression analysis

\begin{tabular}{|c|c|c|c|c|}
\hline \multirow[b]{3}{*}{ Variables } & \multirow{2}{*}{\multicolumn{2}{|c|}{ DFS }} & & \\
\hline & & & \multicolumn{2}{|l|}{ OS } \\
\hline & HR $(95 \%$ CI $)$ & P-value & HR $(95 \%$ CI $)$ & P-value \\
\hline Beclin 1 (positive vs. negative) & $0.537(0.187-1.540)$ & 0.248 & $0.509(0.146-1.771)$ & 0.289 \\
\hline pAkt (positive vs. negative) & $0.148(0.051-0.427)$ & 0.000 & $0.331(0.093-1.173)$ & 0.087 \\
\hline Age ( $\geq 50$ vs. $<50$ years $)$ & $0.731(0.229-2.334)$ & 0.597 & $0.768(0.198-2.972)$ & 0.702 \\
\hline Clinical stage (I+II vs. III) & $0.293(0.098-0.874)$ & 0.028 & $0.165(0.048-0.571)$ & 0.004 \\
\hline Tumor size $(\geq 5$ vs. $<5 \mathrm{~cm})$ & $0.530(0.119-2.369)$ & 0.406 & $0.222(0.071-1.571)$ & 0.165 \\
\hline ER (positive vs. negative) & $1.205(0.418-3.473)$ & 0.730 & $1.655(0.479-5.717)$ & 0.426 \\
\hline PR (positive vs. negative) & $1.543(0.535-4.447)$ & 0.422 & $2.696(0.697-10.429)$ & 0.151 \\
\hline HER2 (positive vs. negative) & $0.444(0.149-1.328)$ & 0.146 & $0.593(0.153-2.294)$ & 0.449 \\
\hline Lymph node status (N1-N3 vs. N0) & $0.462(0.160-1.333)$ & 0.153 & $0.434(0.122-1.538)$ & 0.196 \\
\hline
\end{tabular}

ER, estrogen receptor; PR, progesterone receptor; HER2, human epidermal growth factor receptor 2; TNBC, triple-negative breast cancer; pAkt, phosphorylated RAC- $\alpha$ serine/threonine-protein kinase; HR, hazard ratio; CI, confidence interval.

Table V. Multivariate Cox regression analysis of survival of 90 patients with breast cancer.

\begin{tabular}{|c|c|c|c|c|}
\hline \multirow[b]{3}{*}{ Variables } & \multicolumn{4}{|c|}{ Multivariate Cox regression analysis } \\
\hline & \multicolumn{2}{|c|}{ DFS } & \multicolumn{2}{|c|}{ OS } \\
\hline & HR $(95 \%$ CI $)$ & P-value & $\operatorname{HR}(95 \% \mathrm{CI})$ & P-value \\
\hline pAkt (positive vs. negative) & $0.120(0.040-0.355)$ & $<0.001$ & $0.246(0.067-0.911)$ & 0.036 \\
\hline Clinical stage (I+II vs. III) & $0.208(0.067-0.646)$ & 0.007 & $0.134(0.037-0.482)$ & 0.002 \\
\hline
\end{tabular}

pAkt, phosphorylated RAC- $\alpha$ serine/threonine-protein kinase; HR, hazard ratio; CI, confidence interval; OS, overall survival; DFS, disease-free survival.

A

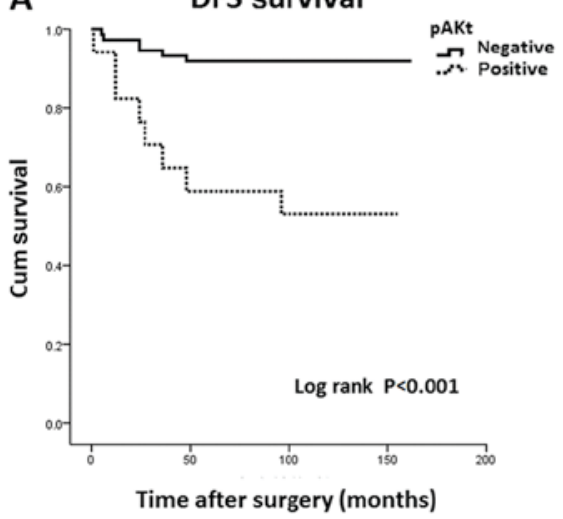

B

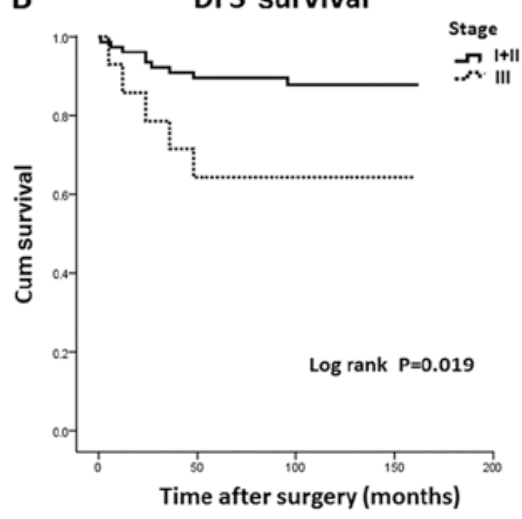

C OS survival

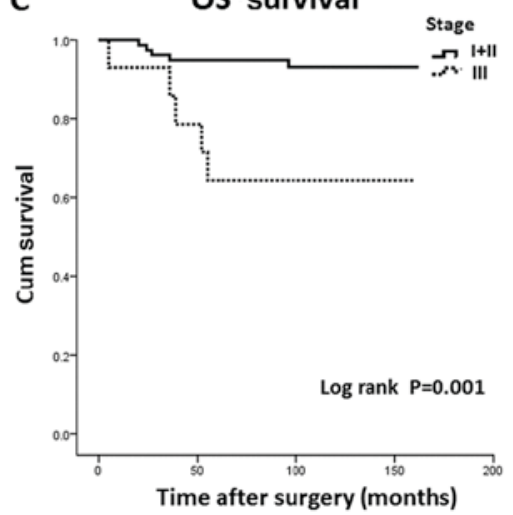

Figure 2. Kaplan-Meier analysis of survival in patients with invasive ductal breast cancer. (A) Survival analysis revealed that the patients with pAkt expression exhibited significantly shorter DFS times (97.12 years) compared with those negative to pAKt expression (150.64 years) (log rank, P<0.001). (B) The patients in clinical stage (I+II) exhibited significantly longer DFS times (146.15 years) compared with those in clinical stage III (111.79 years) (log rank, P=0.019). (C) The patients in clinical stage (I+II) exhibited significantly longer OS times (153.70 years) compared with those in clinical stage III (116.21 years) (log rank, $\mathrm{P}=0.001)$. pAkt, phosphorylated RAC- $\alpha$ serine/threonine-protein kinase; OS, overall survival; DFS, disease-free survival.

\section{Discussion}

Multiple factors have been identified to be associated with breast cancer carcinogenesis, progression, metastasis and recurrence; however, the precise underlying molecular mechanisms remain poorly understood. Therefore, sensitive and specific prognostic indicators for breast cancer are required in clinical practice. 
Overexpression of the PI3K/Akt signaling pathway proteins has been identified in several cancer types (20), including breast cancer. Thus, the present study also detected the activation of the PI3K/Akt pathway in breast cancer tissues, which was not present in normal paracancerous tissues. pAkt was detected in 17 (18.9\%) patient samples by immunohistochemical analyses, which was lower compared with that reported in previous study demonstrating that the PI3K/Akt pathway is activated in half of these tumors $(21,22)$. The difference in results obtained may have been due to the different pathological types or clinical stages studies. Additionally, no significant association between pAkt expression and any of the clinicopathological parameter examined was observed in the present study. Notably, the clinical value of pAkt has been noted in previous studies on certain cancer types, including ovarian cancer, while, others, including the present study did not (23). The reason in differences may be due to the small cohort size in the current study.

The prognostic value of pAkt in invasive ductal breast cancer was detected next using survival analysis. The results of the present study revealed that patients with pAkt expression exhibited significantly shorter DFS times compared with those negative for pAkt. Cox regression analysis indicated pAkt expression was an independent risk factor associated with shorter DFS and OS times, indicating pAkt expression was associated with a poor prognosis, and may be used as a potential prognostic biomarker in invasive ductal breast cancer. However, these results oppose those demonstrated by a previous study by Badve et al (15), which demonstrated that nuclear localization of pAkt was associated with a more improved outcome in patients with breast cancer. Previously, different expression patterns of nuclear and cytoplasmic pAkt were observed, and it was speculated that pAkt has different actions depending on its subcellular localization (24). Only nuclear localized pAkt has been demonstrated to predict a more improved prognosis (24). In the present study, pAkt expression was detected primarily in the cytoplasm, which may explain why pAkt expression was able to predict a poor prognosis in patients with breast cancer. In addition, other reasons may be the due to the different genetic background and pathological types in the present study versus other studies. To the best of our knowledge, this is the first study to identify cytoplasmic pAkt expression as a potential biomarker to predict poor prognosis in Chinese women with invasive ductal breast cancer. Considering this, the detection of pAkt expression in breast cancer tissue may provide additional information on the prognosis, which may favor early detection of the development of recurrence and distant metastasis, and allow for successful salvage treatments for these patients in a timely manner.

Autophagy is a physiological process in eukaryotic cells, and is essential to maintaining the stability of the internal environment and adapting to external environment changes. It has been revealed that the expression changes of autophagy-associated proteins may contribute to the development or progression of cancer (25). Beclin 1 is well-known as a reliable autophagy-related protein in various cancer types, and is involved in the signaling pathway that activates autophagy and in the initial step of autophagosome formation, leading to tumor development, metastasis and recurrence (26). In the current study, Beclin 1 expression was detected in 33 (36.7\%) breast cancer samples, but not detected in any normal samples, indicating the upregulation of autophagy in breast cancer. While other studies have demonstrated that Beclin 1 expression was frequently decreased in breast cancer compared with that in normal cells, decreased Beclin 1 was also observed in other cancer types, including hepatocellular carcinoma and lung cancer (26-28).

An in vivo study has demonstrated that Beclin 1 knockdown provides an oncogenic stimulus, causing malignant transformation and spontaneous tumors (29). However, other studies have reported that autophagy is upregulated in tumors, including gastrointestinal, pancreatic and gallbladder cancer (30-32). In addition, the results in the present study revealed that Beclin 1 expression was not significantly associated with any clinicopathological parameter, including age, tumor size, clinical stage, lymph node metastasis, ER, PR and HER2 status in patients with breast cancer. Furthermore, no significant differences in DFS and OS rates were noted between the Beclin 1-positive and -negative groups. Cox regression analysis identified no significant association between Beclin 1 expression and clinical prognosis. Similar results have been observed in other cancer types, including cervical and lung cancer (33). Conversely, other studies have revealed that Beclin 1 exhibits significant negative associations with clinical stage, lymph node metastasis and the prognosis of cervical cancer (34), as well as pancreatic cancer (31), gastric carcinoma (35), esophageal squamous cell carcinoma (36), and hepatocellular carcinoma (37).

These controversial findings may be explained by the biphasic function of autophagy during carcinogenesis. Autophagy is implicated in different functions in diverse tumors and different phases of tumor development. For instance, autophagy may suppress tumorigenesis in the early phase of tumor development; however, autophagy may be a key tumor cell survival mechanism in response to microenvironmental stress in the late phase of tumor development. Certain studies have revealed that autophagy enhances the survival of tumor cells, in vitro and in vivo, under the condition of metabolic stress $(38,39)$, while, other studies indicated that autophagy inhibits tumor cells, and autophagy defects were associated with increasing carcinogenesis $(40,41)$. Previous studies demonstrated that autophagy represents a key survival mechanism in which tumor cells respond to microenvironmental stress during cancer development and promote tumor cell survival (42). Based on the results of the present study, we propose that autophagy is upregulated in invasive ductal breast cancer. Although, the small number of cancer tissue samples included in the present may limit the interpretation of these results. Therefore, large sample studies should be conducted to confirm the role of autophagy in invasive ductal breast cancer.

Additionally, the present study demonstrated that clinical stage III was an independent risk factor associated with shorter DFS and OS times, consistent with previous findings (43). There were certain limitations in the present study. First, the immunohistochemistry method on tissue samples is a semi-quantitative method, thus not highly informative. However, the primary aim of this study was to identify whether pAkt and Beclin 1 expression in breast cancer tissue were potential prognostic biomarkers for breast cancer. Furthermore, the expression of these genes in tissue sample 
may be more objective and useful compared with the detection in tumor cells. Second, the number of cases, particularly the mortality cases in the study was limited. In the future studies, a larger patient cohort is required to further evaluate and validate these promising findings.

To conclude, the results of the present study indicated that pAkt expression was independently associated with a poor outcome in patients with invasive ductal breast cancer, suggesting the use of pAkt as a potential prognostic biomarker. The detection of pAkt expression in breast cancer tissue may provide useful information on the prognosis, which may favor early detection of the development of recurrence and distant metastasis, and allow for successful salvage treatments for these patients in a timely manner.

\section{Acknowledgements}

The present study was partially supported by the Youth Foundation of Shanghai Municipal Health Bureau (grant no. 2012y144).

\section{References}

1. Jemal A, Bray F, Center MM, Ferlay J, Ward E and Forman D: Global cancer statistics. CA Cancer J Clin 61: 69-90, 2011.

2. Li CI, Anderson BO, Daling JR and Moe RE: Trends in incidence rates of invasive lobular and ductal breast carcinoma. JAMA 289: 1421-1424, 2003.

3. Kohler BA, Ward E, McCarthy BJ, Schymura MJ, Ries LA, Eheman C, Jemal A, Anderson RN, Ajani UA and Edwards BK: Annual report to the nation on the status of cancer, 1975-2007, featuring tumors of the brain and other nervous system. J Nat Cancer Inst 103: 714-736, 2011.

4. Wang YC, Wei LJ, Liu JT, Li SX and Wang QS: Comparison of cancer incidence between China and the USA. Cancer Biol Med 9: 128-132, 2012.

5. Linos E, Spanos D, Rosner BA, Linos K, Hesketh T, Qu JD, Gao YT, Zheng W and Colditz GA: Effects of reproductive and demographic changes on breast cancer incidence in China: A modeling analysis. J Natl Cancer Inst 100: 1352-1360, 2008.

6. McPherson K, Steel CM and Dixon JM: ABC of breast diseases. Breast cancer-epidemiology, risk factors, and genetics. BJM 321 624-628, 2000.

7. Chia KS, Reilly M, Tan CS, Lee J, Pawitan Y, Adami HO, Hall P and Mow B: Profound changes in breast cancer incidence may reflect changes into a Westernized lifestyle: A comparative population-based study in Singapore and Sweden. Int J Cancer 113: 302-306, 2005

8. Pérez-Tenorio G and Stål O; Southeast Sweden Breast Cancer Group: Activation of AKT/PKB in breast cancer predicts a worse outcome among endocrine treated patients. Br J Cancer 86: $540-545,2002$

9. Song G, Ouyang $\mathrm{G}$ and Bao S: The activation of Akt/PKB signaling pathway and cell survival. J Cell Mol Med 9: 59-71, 2005.

10. Roudier E, Mistafa O and Stenius U: Statins induce mammalian target of rapamycin mTOR)-mediated inhibition of Akt signaling and sensitize p53-deficient cells to cytostatic drugs. Mol Cancer Ther 5: 2706-2715, 2006

11. Mondesire WH, Jian W, Zhang H, Ensor J, Hung MC, Mills GB and Meric-Bernstam F: Targeting mammalian target of rapamycin synergistically enhances chemotherapy-induced cytotoxicity in breast cancer cells. Clin Cancer Res 10: 7031-7042, 2004

12. Vestey SB, Sen C, Calder CJ, Perks CM, Pignatelli M and Winters ZE: Activated Akt expression in breast cancer: Correlation with p53, Hdm2 and patient outcome. Eur J Cancer 41: 1017-1025, 2005.

13. Tokunaga E, Kimura Y, Oki E, Ueda N, Futatsugi M, Mashino K, Yamamoto M, Ikebe M, Kakeji Y, Baba H and Maehara Y: Akt is frequently activated in HER2/neu-positive breast cancers and associated with poor prognosis among hormone-treated patients. Int J Cancer 118: 284-289, 2006.
14. Benesch C, Schneider C, Voelker HU, Kapp M, Caffier H, Krockenberger M, Dietl J, Kammerer U and Schmidt M: The clinicopathological andprognostic relevance of pyruvate kinase M2 and pAkt expression in breast cancer. Anticancer Res 30: 1689-1694, 2010

15. Badve S, Collins NR, Bhat-Nakshatri P, Turbin D, Leung S, Thorat M, Dunn SE, Geistlinger TR, Carroll JS, Brown M, et al: Subcellular localization ofactivated AKT in estrogen receptor- and progesterone receptor-expressing breastcancers: Potential clinical implications. Am J Pathol 176: 2139-2149, 2010.

16. Levine B and Kroemer G: Autophagy in the pathogenesis of disease. Cell 132: 27-42, 2008.

17. Mizushima N, Levine B, Cuervo AM and Klionsky DJ: Autophagy fights disease through cellular self-digestion. Nature 451: 1069-1075, 2008.

18. Nishimura K, Semba S, Aoyagi K, Sasaki H and Yokozaki H: Mesenchymal stem cells provide an advantageous tumor microenvironment for the restoration of cancer stem cells. Pathobiology 79: 290-306, 2012.

19. Singletary SE, Allred C, Ashley P, Bassett LW, Berry D, Bland KI, Borgen PI, Clark GM, Edge SB, Hayes DF, et al: Staging system for breast cancer: Revisions for the 6th adition of the AJCC cancer staging manual. Surg Clin North Am 83: 803-819, 2003.

20. Markman B, Atzori F, Pérez-García J, Tabernero J and Baselga J: Status of PI3K inhibition and biomarker development in cancer therapeutics. Ann Oncol 21: 683-691, 2010.

21. Altomare DA, Wang HQ, Skele KL, De Rienzo A, Klein-Szanto AJ, Godwin AK and Testa JR: AKT and mTOR phosphorylation is frequently detectedin ovarian cancer and can be targeted to disrupt ovarian tumor cell growth. Oncogene 23: 5853-5857, 2004.

22. Verhaak RG, Tamayo P, Yang JY, Hubbard D, Zhang H, Creighton CJ, Fereday S, Lawrence M, Carter SL, Mermel $\mathrm{CH}$, et al: Prognostically relevant gene signatures of high-grade serouso varian carcinoma. J Clin Invest 123: 517-525, 2013.

23. Woenckhaus J, Steger K, Sturm K, Münstedt K, Franke FE and Fenic I: Prognostic value of PIK3 CA and phosphorylated AKT expression in ovarian cancer. Virchows Arch 450: 387-395, 2007.

24. Azim HA, Kassem L, Treilleux I, Wang Q, El Enein MA, Anis SE and Bachelot T: Analysis of PI3K/mTOR pathway biomarkers and their prognostic value in women with hormone receptor-positive, HER2-negative early breast cancer. Transl Oncol 9: 114-123, 2016.

25. Chen J, Xi B, Zhao Y, Yu Y, Zhang J and Wang C: High-mobility group protein B1 (HMGB1) is a novel biomarker for human ovarian cancer. Gynecol Oncol 126: 109-117, 2012.

26. Jiang ZF, Shao LJ, Wang WM, Yan XB and Liu RY: Decreased expression of Beclin-1 and LC3 in human lung cancer. Mol Biol Rep 39: 259-267, 2012.

27. Zarzynska JM: The importance of autophagy regulation in breast cancer development and treatment. Biomed Res Int 2014: 710345, 2014.

28. Ding ZB, Shi YH, Zhou J, Qiu SJ, Xu Y, Dai Z, Shi GM, Wang XY, Ke AW, Wu B and Fan J: Association of autophagy defect with a malignant phenotype and poor prognosis of hepatocellular carcinoma. Cancer Res 68: 9167-9175, 2008.

29. Dalby KN, Tekedereli I, Lopez-Berestein G and Ozpolat B: Targeting the prodeath and prosurvival functions of autophagy as novel therapeutic strategies in cancer. Autophagy 6: 322-329, 2010.

30. Yoshioka A, Miyata H, Doki Y, Yamasaki M, Sohma I, Gotoh K, Takiguchi S, Fujiwara Y, Uchiyama Y and Monden M: LC3, an autophagosome marker, is highly expressed in gastrointestinal cancers. Int J Oncol 33: 461-468, 2008.

31. Fujii S, Mitsunaga S, Yamazaki M, Hasebe T, Ishii G, Kojima M, Kinoshita T, Ueno T, Esumi $\mathrm{H}$ and Ochiai A: Autophagy is activated in pancreatic cancer cells and correlates with poor patient outcome. Cancer Sci 99: 1813-1819, 2008.

32. Park JY, Kim HS, Cho H, Kim NC, Chae KH, Park WS and Kim YW: Clinicopathologic correlation of autophagy-related Beclin-1 expression in gallbladder cancer. Hepatogastroenterology 61: 1494-1500, 2014.

33. Jiang ZF, Shao LJ, Wang WM, Yan XB and Liu RY: Decreased expression of Beclin-1 and LC3 in human lung cancer. Mol Biol Rep 39: 259-267, 2012.

34. Cheng HY, Zhang YN, Wu QL, Sun XM, Sun JR and Huang X: Expression of beclin 1, an autophagy-related protein, in human cervical carcinoma and its clinical significance. Eur J Gynaecol Oncol 33: 15-20, 2012 
35. Chen YB, Hou JH, Feng XY, Chen S, Zhou ZW, Zhang XS and Cai MY: Decreased expression of Beclin 1 correlates with a metastatic phenotypic feature and adverse prognosis of gastric carcinomas. J Surg Oncol 105: 542-547, 2012.

36. Chen Y, Lu Y, Lu C and Zhang L: Beclin-1 expression is a predictor of clinical outcome in patients with esophageal squamous cell carcinoma and correlated to hypoxia-inducible factor HIF)-1alpha expression. Pathol Oncol Res 15: 487-493, 2009.

37. Osman NA, Abd El-Rehim DM and Kamal IM: Defective Beclin-1 and elevated hypoxia-inducible factor (HIF)-1a expression are closely linked to tumorigenesis, differentiation, and progression of hepatocellular carcinoma. Tumour Biol 36: 4293-4299, 2015.

38. Mathew R, Karantza-Wadsworth V and White E: Role of autophagy in cancer. Nat Rev Cancer 7: 961-967, 2007.

39. Degenhardt K, Mathew R, Beaudoin B, Bray K, Anderson D, Chen G, Mukherjee C, Shi Y, Gélinas C, Fan Y, et al: Autophagy promotes tumor cell survival and restricts necrosis, inflammation, and tumorigenesis. Cancer Cell 10: 51-64, 2006.
40. Lorin S, Hamaï A, Mehrpour M and Codogno P: Autophagy regulation and its role in cancer. Semin Cancer Biol 23: 361-379, 2013.

41. Choi AM, Ryter SW and Levine B: Autophagy in human health and disease. N Engl J Med 368: 651-662, 2013.

42. Liang XH, Jackson S, Seaman M, Brown K, Kempkes B, Hibshoosh $\mathrm{H}$ and Levine B: Induction of autophagy and inhibition of tumorigenesis by beclin 1. Nature 402: 672-676, 1999.

43. Zhang Y, Zhang Y, Xiu HQ, et al: Clinical features of TNM staging of triple negative breast cancer and risk factors affecting its prognosis. Chin J Breast Dis 6: 30-35, 2012.

c) (i) This work is licensed under a Creative Common Attribution-NonCommercial-NoDerivatives 4.0 International (CC BY-NC-ND 4.0) License. 